\title{
Nationwide epidemiological characteristics of chronic fatigue syndrome in South Korea
}

\author{
Eun-Jin Lim ${ }^{2 \dagger}$, Jin-Seok Lee ${ }^{1 \dagger}$, Eun-Jung Lee ${ }^{3}$, Seok-Ju Jeong ${ }^{4}$, Ho-Young Park ${ }^{4}$, Yo-Chan Ahn ${ }^{5}$ and \\ Chang-Gue Son ${ }^{1 *}$ (D)
}

\begin{abstract}
Background: Chronic fatigue syndrome (CFS) is a long-term disabling illness accompanied by medically unexplained fatigue. This study aimed to explore the epidemiological characteristics of CFS in South Korea.

Methods: Using the nationwide medical records provided by the Korean Health Insurance Review \& Assessment Service (HIRA), we analyzed the entire dataset for CFS patients diagnosed by physicians in South Korea from January 2010 to December 2020.

Results: The annual mean incidence of CFS was estimated to be $44.71 \pm 6.10$ cases per 100,000 individuals [95\% Cl: $40.57,48.76$ ], and the prevalence rate was $57.70 \pm 12.20$ cases per 100,000 individuals [95\% Cl: 49.40, 65.79]. These two rates increased by 1.53- and 1.94-fold from 2010 to 2020, respectively, and showed an increasing trend with aging and an approximately 1.5 -fold female predominance.

Conclusions: This study is the first to report the nationwide epidemiological features of CFS, which reflects the clinical reality of CFS diagnosis and care in South Korea. This study will be a valuable reference for studies of CFS in the future.
\end{abstract}

Keywords: Chronic fatigue syndrome, CFS, ME/CFS, Incidence, Prevalence, South Korea, epidemiology

\section{Background}

Uncontrolled chronic fatigue substantially impairs health-related quality of life (QoL), especially in cases of medically unexplained fatigue compared to explained chronic fatigue [1]. Chronic fatigue syndrome (CFS, also called 'myalgic encephalomyelitis' (ME)) is the most debilitating form of medically unexplained fatigue, which leads to a house- or bed-bound state in 25 to $29 \%$ of patients [2] and presents a sevenfold higher risk of suicide than healthy subjects [3]. The etiology of CFS is uncertain, and to date, there has been a failure to

\footnotetext{
*Correspondence: ckson@dju.ac.kr

†Eun-Jin Lim and Jin-Seok Lee authors equally contributed to this study ${ }^{1}$ Institute of Bioscience \& Integrative Medicine, College of Korean Medicine, Daejeon Oriental Hospital of Daejeon University, Daedeok-Daero 176, Seo-Gu, Daejeon 35235, Republic of Korea Full list of author information is available at the end of the article
}

establish concrete pathophysiology, objective diagnostics, or therapeutics [4].

The prevalence of chronic fatigue is approximately $10 \%$ in the general population [5], while the CFS prevalence rate is estimated to be $1 \%$, although this varies depending on gender, study population, ethnicity and case definition [6]. Among those factors, case definition and diagnostic methods particularly affect the prevalence rate of CFS; for example, rates of $0.9 \%$ by CDC- 1994 vs. $0.2 \%$ by Holmes' definitions and $1.1 \%$ via interviews $v$ s. $0.1 \%$ via physician diagnosis were reported [7]. Some studies reported a 1.5 - to 2.0-fold female predominance attributable to sex-hormonal responses and two age peaks at 10-19 and 30-39 years $[8,9]$.

CFS is now considered a serious health problem in the form of a complex multisystem neurological disorder, and the Institute of Medicine (IOM) emphasized the need for national medical and scientific efforts in CFS original author(s) and the source, provide a link to the Creative Commons licence, and indicate if changes were made. The images or other third party material in this article are included in the article's Creative Commons licence, unless indicated otherwise in a credit line to the material. If material is not included in the article's Creative Commons licence and your intended use is not permitted by statutory regulation or exceeds the permitted use, you will need to obtain permission directly from the copyright holder. To view a copy of this licence, visit http://creativecommons.org/licenses/by/4.0/. The Creative Commons Public Domain Dedication waiver (http://creativeco mmons.org/publicdomain/zero/1.0/) applies to the data made available in this article, unless otherwise stated in a credit line to the data. 
research [10]. To date, CFS-related studies have been mainly conducted in the USA and UK. To date, five studies have assessed the prevalence of CFS in South Korea; however, these studies were conducted using relatively small populations and have not been updated since 2008 [11]. Defining an accurate prevalence rate and its related factors are essential for exploring the pathophysiological basis of CFS [12]. Meanwhile, there is still a tendency for physicians to hesitate or refuse to diagnose an individual with CFS due to a lack of knowledge or understanding of CFS [13-15].

Therefore, this study aimed to explore the nationwide clinic-based comprehensive epidemiological features of CFS in South Korea.

\section{Methods}

\section{Data sources}

South Korea has a national health insurance system that covers the entire population of Korea. Accurate medical information for the entire population is deposited and publicly available by the Health Insurance Review \& Assessment Service (HIRA) in South Korea [HIRA]. Using the Healthcare Big Data Hub of HIRA, we extracted the entire dataset for health services to patients who had been diagnosed or treated for postviral fatigue syndrome (PVFS; this is the same as chronic fatigue syndrome, ICD10-G93.3) during the past 11 years (from January 1st, 2010, to December 31st, 2020).

\section{Data analysis}

We analyzed the epidemiological features of CFS among the entire South Korean population using HIRA-derived datasets to address the following questions: absolute frequency of CFS based on the year, sex and age and in relation to whole South Korean population, treatment periods associated with CFS after 1st diagnosis on 2011, and any specific disease profile present before the initial diagnosis with CFS. Regarding the estimation of incidence rates, we considered an event a 'new' diagnosis of CFS in each year, if there was no preceding diagnosis of CFS in the patient's medical record. For the prevalence of CFS, we extracted all cases of CFS diagnosis in each year.

\section{Statistical analysis}

The annual incidence rate and prevalence of CFS, including $95 \%$ confidence intervals, were calculated by the number of recorded diagnosis cases divided by the number in the entire general population for each corresponding year. Subsequently, the overall rate with a $95 \%$ confidence interval ( $95 \% \mathrm{CI}$ ) per 100,000 patients was calculated. The data for the whole population were obtained from the Korean Statistical Information Service [16]. Statistical analyses of any differences between males

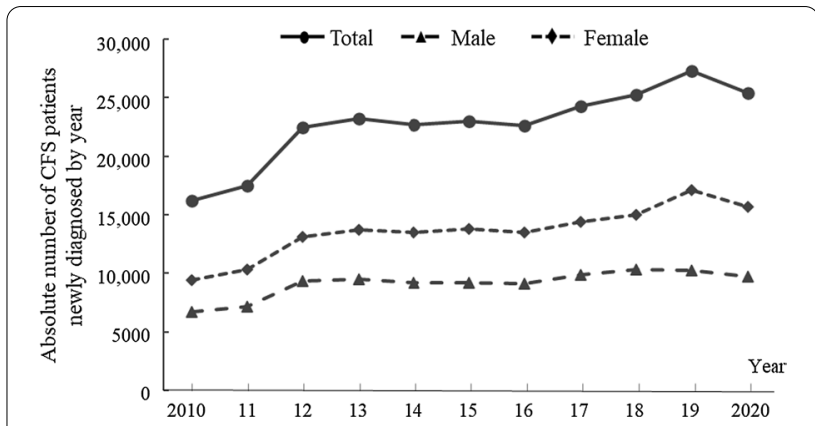

Fig. 1 Number of patients newly diagnosed with CFS in each year. The absolute number of CFS cases from 2010 to 2020 is presented

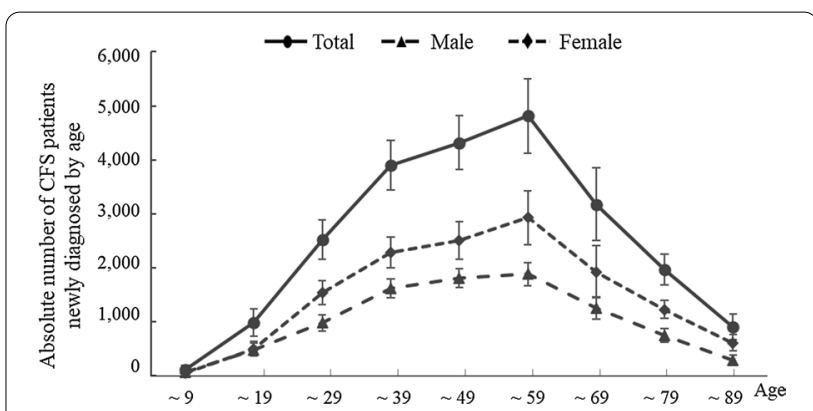

Fig. 2 Mean number of patients newly diagnosed with CFS by age. The mean number of CFS cases by age from 2010 to 2020 is presented

and females were conducted by the Mann-Whitney U test with the SPSS statistical software package version 18.0 (SPSS Inc., Chicago, IL, USA).

\section{Results}

Absolute number of patients newly diagnosed with CFS in each year

The mean number of patients newly diagnosed with CFS in each year was $22,720 \pm 3284$, which showed a consistent female predominance of 1.49-fold (males $9122 \pm 1152$ vs. females $13,598 \pm 2179$ ) over 11 years. This physician diagnosis-derived annual incidence of CFS increased 1.57 -fold between $2010(16,175)$ and $2020(25,403)$ and was slightly higher in females (1.66-fold) than in males (1.44-fold) (Fig. 1).

\section{Age-related features of a new CFS diagnosis}

Regarding the age-related frequency of CFS diagnosis, the absolute number peaked in the 50- to 59-year-old population in both males and females. Females were predominant compared to males across all age populations, with the exception of those before 10 years of age (Fig. 2). 
Table 1 Summary of demographic features of CFS patients in South Korea

\begin{tabular}{|c|c|c|c|c|}
\hline Items & Total & Male & Female & F/M ratio \\
\hline Entire population & $50,812,880 \pm 522,785$ & $25,389,442 \pm 227,238$ & $25,423,437 \pm 295,787$ & - \\
\hline Mean N. of new CFS patients & $22,720 \pm 3,284$ & $9,122 \pm 1,152$ & $13,598 \pm 2176$ & 1.49-folds \\
\hline $\begin{array}{l}\text { Incidence rate (per } 10^{5} \text { ) } \\
\text { ( } 95 \% \text { confidence interval) } \\
\text { In } 2010 \text { vs. } 2020 \text { year } \\
\text { (Change during } 11 \text {-yrs) }\end{array}$ & $\begin{array}{l}44.71 \pm 6.10 \\
{[40.57 ; 48.76]} \\
32.43 \text { vs. } 49.47 \\
\text { (1.53-folds) }\end{array}$ & $\begin{array}{l}35.93 \pm 4.30 \\
{[33.01 ; 38.79]} \\
26.97 \text { vs. } 37.90 \\
(1.41 \text {-folds })\end{array}$ & $\begin{array}{l}53.49 \pm 8.05 \\
{[48.00 ; 58.82]} \\
37.90 \text { vs. } 60.98 \\
\text { (1.61-folds) }\end{array}$ & $\begin{array}{l}\text { 1.49-folds } \\
{[1.43 ; 1.54]}\end{array}$ \\
\hline Mean N. of recorded CFS patients & $29,320 \pm 6,456$ & $11,747 \pm 2,344$ & $17,573 \pm 4,132$ & 1.50 -folds \\
\hline $\begin{array}{l}\left.\text { Prevalence rate (per } 10^{5}\right) \\
\text { ( } 95 \% \text { confidence interval) } \\
\text { In } 2010 \text { vs. } 2020 \text { year } \\
\text { (Change during } 11-y r s)\end{array}$ & $\begin{array}{l}57.70 \pm 12.20 \\
{[49.40 ; 65.79]} \\
36.15 \text { vs. } 76.10 \\
\text { (1.94-folds) }\end{array}$ & $\begin{array}{l}46.27 \pm 8.88 \\
{[40.23 ; 52.17]} \\
30.29 \text { vs. } 53.80 \\
\text { (1.78-folds) }\end{array}$ & $\begin{array}{l}69.12 \pm 15.55 \\
{[58.52 ; 79.41]} \\
42.03 \text { vs. } 86.31 \\
\text { (2.05-folds) }\end{array}$ & $\begin{array}{l}\text { 1.49-folds } \\
{[1.44 ; 1.53]}\end{array}$ \\
\hline $\begin{array}{l}\text { Mean treatment duration } \\
\text { (month) }\end{array}$ & $\begin{array}{l}9.13 \\
{[4.63 ; 13.63]}\end{array}$ & $\begin{array}{l}8.15 \\
{[1.73 ; 14.57]}\end{array}$ & $\begin{array}{l}9.80 \\
{[3.41 ; 16.19]}\end{array}$ & 1.20-folds \\
\hline
\end{tabular}

The mean data resulted from 11 -year recorded cases between 2010 and $2020 .{ }^{*}, \mathrm{P}<0.001$

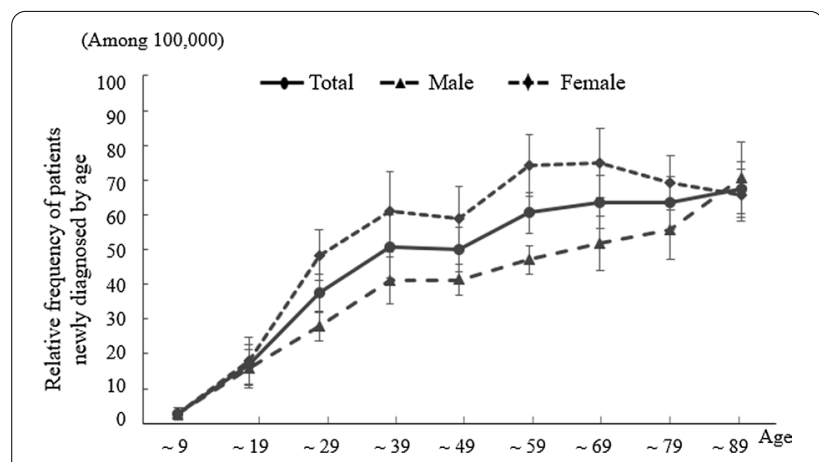

Fig. 3 Incidence rate of CFS by age. The number of newly diagnosed CFS cases per 100,000 persons by age from 2010 to 2020 is presented

\section{Relative frequency of patients newly diagnosed with CFS to the whole population}

When we analyzed CFS data compared to the whole population, the average annual incidence of CFS was estimated to be $44.71 \pm 6.10$ cases per 100,000 individuals [95\% CI: 40.57, 48.76]. There was an increase of 1.53-fold between 2010 and 2020 (from 32.43 to 49.47) (Table 1). Females $(53.49 \pm 8.05,95 \%$ CI: $48.00,58.82]$ were 1.49 fold more likely than males $(35.93 \pm 4.30,95 \%$ CI: 33.01 , 38.79 ] to be diagnosed, and this female-predominant pattern was consistent across the population aged 10 to 79 years old. The peak frequency in males was in the age group older than 80 years old (relative frequency of 70.7 patients), while females reached a relative frequency of 70.7 patients in the age group of 60 to 69 years old (Fig. 3).

\section{Treatment duration of CFS after initial diagnosis}

To estimate the period during which CFS patients underwent treatment after the initial diagnosis, we analyzed individual medical records using only the patients

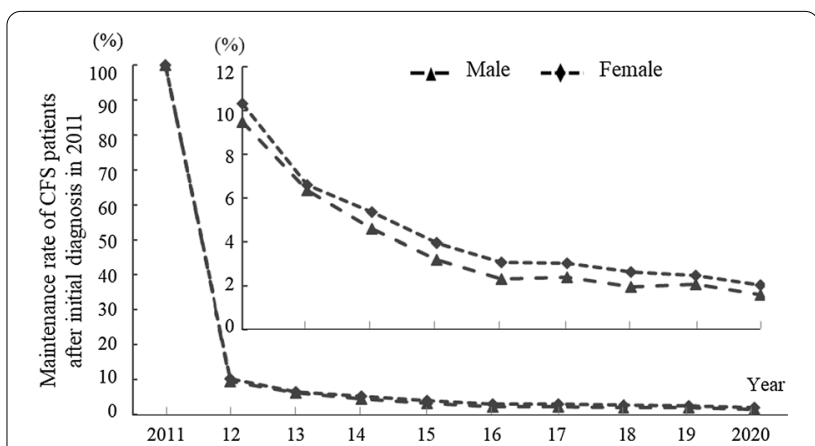

Fig. 4 Treatment duration of CFS after being newly diagnosed in 2011. After an initial diagnosis in 2011, the percentage of CFS patients receiving treatment based on medical records through 2020 is presented. (The subfigure indicates the male and female treatment duration of CFS from 2012 to 2020)

diagnosed in 2011. In the subsequent year, only $9.97 \%$ of the patients initially diagnosed with CFS in 2011 were treated for CFS, and the rate continuously decreased to $1.86 \%$ in 2020 . Based on these results, the median treatment duration for CFS seems to be approximately 9.13 months, at least in the clinic. This pattern was observed in both male and female patients, with a slightly higher rate in females than males (Fig. 4).

\section{Prevalence features of CFS by gender, age, and year}

The mean recorded prevalence rate of CFS was $57.70 \pm 12.20$ cases per 100,000 individuals [95\% CI: $49.40,65.79]$, with a 1.49-fold female-predominant trend $(69.12 \pm 15.55,95 \% \mathrm{CI}: 58.52,79.41]$ compared to males $(46.27 \pm 8.88,95 \% \mathrm{CI}: 40.23,52.17)$. Over the past 11 years, this prevalence increased approximately twofold, and this increase was the same in males (1.78-fold) 
and females (2.05-fold) (Table 1). Similar to the annual incidence rates, the prevalence rate in males peaked at age of more than 80 years old ( 96.47 cases per 100,000 people) and in females in the 60- to 69-year-old range (107.90 cases per 100,000 people) (Fig. 3 ).

\section{Discussion}

Signing up for the national health insurance system is mandatory for every citizen and every medical clinic in South Korea; thus, all data regarding diagnosis and treatment are deposited in the HIRA system of the Korean government. These resources are also available for beneficial public use via the Healthcare Big Data Hub of HIRA, from which we obtained the datasets for CFS. We herein produced the annual frequency of CFS diagnosis and the corresponding period of treatment by gender, age and year.

Based on the recorded diagnosis by physicians, the mean annual incidence rate of CFS in South Korea was 44.71 cases per 100,000 persons (Table 1 ). This annual incidence rate is higher than those reported in other studies. A previous study conducted in Wichita in the USA showed a much higher incidence rate of 180 per 100,000 person-years by the CDC 1994 case definition [17]. This study was conducted via a 1-year follow-up telephone interview and clinical examination among the general population. Another US study revealed 13.2 per 100,000 person-years using one set of regional medical records (Olmsted County in Minnesota) from 1998 to 2002 [18]. The incidence and prevalence of CFS could differ based on the applied case definitions [19]. These two studies adapted the same CDC 1994 criteria; however, they showed a large difference in CFS incidence, which might have been caused by study methods and population (survey from general population vs. retrospective medical record review). In a similar format as our study using the General Practice Research Database (GPRD) that includes data from participating general practices across the UK, the annual incidence was 27.0 CFS/ME/ PVFS cases per 100,000 persons for the period 20012013 [20].

On the other hand, the prevalence of CFS is known to be approximately $1 \%$ worldwide [6]. Our previous metaanalysis using 56 datasets reported an approximately $0.89 \%$ global prevalence of CFS in the general population [7]. The present results, however, unexpectedly showed a very low prevalence, only 57.70 cases per 100,000 persons, equal to $0.057 \%$ of the general population (Table 1 ). This large gap might have been a result of the methods used in assessing the prevalence, namely, a questionnaire-based survey for the general population versus physician-diagnosed recorded patients. In fact, most of the studies in our previous meta-analysis used interviews, and the subgroup prevalence based on physician diagnosis (6 datasets) showed a $0.09 \%$ prevalence [7]. The early diagnosis of CFS in primary care is critically important along with tailored management; however, many medical doctors in the USA are reluctant to make a diagnosis due to the limited knowledge of the disease [21]. Moreover, a certain number of physicians tend to reject CFS as an actual physical disease, which disrupts the reliable relationship between medical providers and patients suffering from CFS [22, 23]. There remains the poor conceptual status of CFS among physicians, and South Korea is no exception, and perhaps worse, which may be a cause of South Korean CFS patients avoiding medical care [24].

Additionally, the loose definition of CFS can be another cause of the low rate of physician diagnosis. For example, the ICD-10 included ME but not CFS under PVFS (G93.3). CFS tended to be considered fatigue and miscoded as 'fatigue syndrome' (F48.0) or 'malaise and fatigue' (R53) [24, 25]. As the latest version of the ICD11 (2019) included both ME and CFS under PVFS (8E49), awareness of the illness may be increasing $[19,26]$.

This would be evidenced by the result that less than $10 \%$ of CFS patients initially diagnosed with CFS in 2011 continued treatment based on medical records as CFS patients in the next year (2012), which was down to $1.86 \%$ in 2020 (Fig. 3). The median duration of CFS was reported to be approximately seven years [27], which is much longer than South Korean CFS patients were treated (approximately 9.13 months in clinics; Table 1) based on the present results. In our study, the prevalence rate of CFS was just 1.29-fold higher than its incidence rate, while a US study showed a prevalence rate 5.43fold higher than the incidence rate [18]. If we re-estimate the prevalence rate using a 7-year median duration model, the prevalence rate of South Korean CFS would be approximately 5.1 -fold higher than the incidence rate, resulting in over $0.22 \%$ of the general population. However, we anticipate that South Korean physicians are now more aware of CFS due to the increasing trends in both the incidence rate (1.53-fold) and prevalence rate (1.94fold) (Table 1).

The female predominance, which mainly affects young adults, is a known epidemiologic feature of CFS [7, 28]. In the present study, both the incidence and prevalence rates were 1.49 -fold female predominant $(p<0.001)$ (Table 1), in accordance with the meta-analysis using 56 worldwide datasets [7]. This sex-related difference in CFS incidence/prevalence is supposed to be linked primarily to sex hormones, which is supported by the difference starting at puberty, approximately 13 years of age $[9,29,30]$. Our current results also showed a higher incidence rate in males in the 9-year-old and younger subgroup (when divided into 10-year intervals), while 
the female-predominant pattern was observed after that point (Fig. 3). In contrast to our expectation, the total incidence rate of CFS increased with increases in age, but females peaked at 60 to 69 years old (Fig. 3). These results were somewhat dissimilar to the known facts that this illness is most common in adults between 40 and 60 years old [30]. One study using a large sample of physicians and a hospital-based database showed similar epidemiologic features, an aging-dependent increase in the total prevalence rate but a high prevalence in females between 40 and 59 years of age [31].

This study, however, contains inevitable limitations that we have to be aware of in interpreting the data. The present results for the incidence rate and prevalence rate were much lower than both other reports and our expectation. To date, 5 studies have estimated South Korean CFS prevalence, and these data-derived meta-analyses presented a rate of $0.77 \%$ (95\% CI: $0.34,1.76$; a 13.5 -fold increase over the present rate) along with an over twofold female predominance $(1.31 \%$ in females $v s .0 .60 \%$ in males) [11]. Among the 5 studies, 2 studies used only interviews [32-34] And 3 studies used interviews and medical tests [34-36]. All 5 studies applied CDC-1994 criteria in the CFS diagnosis process, which is the most commonly used criterion in clinics and clinical trials [7, 37]. However, we cannot verify which criteria the physicians used for diagnosis in the present dataset. We additionally examined regional difference (megacities vs. others) and specific profiles of disorders prior to the 1st diagnosis of CFS among the CFS patients, and no significant results were found.

The physician diagnosis-derived present data reflects the clinical reality in South Korea; however, these data might show a large difference from results from small population-based epidemiological studies. One study estimated that $84-91 \%$ of patients suffering from CFS/ ME in the USA were not diagnosed with the disease by physicians [38]. There would be a possibility that CFS patients are less likely to be diagnosed by medical doctors in Korea, while they popularly use of natural remedies including ginseng product or antioxidants. In fact, many antioxidant products showed the antifatigue effects in clinical trials for chronic fatigue or CFS, and a nanoantioxidant therapy is also newly applied [39-41]. To the best of our knowledge, this study is the first to report the nationwide prevalence of CFS without any restrictions, including age.

\section{Conclusions}

We herein characterized the nationwide epidemiological features of CFS reflecting the clinical reality using the entire physician diagnosis-derived datasets in South Korea from 2010 to 2020. The incidence rate of CFS in South Korea was estimated to be $44.71 \pm 6.10$ cases per 100,000 individuals [95\% CI: $40.57,48.76]$, and the prevalence rate was estimated to be $57.70 \pm 12.20$ cases per 100,000 individuals [95\% CI: $49.40,65.79]$. These frequencies increased with aging and showed an approximately 1.5 -fold female predominance. This study is the first to report the nationwide epidemiological features of CFS, which reflects the clinical reality of CFS diagnosis and care in South Korea. This study will be a valuable reference to health care providers and researchers for studies of CFS in the future.

\section{Abbreviations}

CFS: Chronic fatigue syndrome; ME: Myalgic Encephalomyelitis; HIRA: The Korean Health Insurance Review and Assessment Service; CDC: Centers for disease control and prevention.

\section{Acknowledgements}

The authors would like to thank the Ministry of Education, Science and Technology, the National Research Foundation of Korea (2018R1A6A1A03025221) for supporting this research.

\section{Authors' contributions}

$J S L, E J L$ and EJL conducted the literature search, data analysis, and drafting of the manuscript. JSJ and HYP were responsible for data collection and analysis, and YCA performed the statistical analysis. CGS was responsible for supervision of the study and contributed to writing the manuscript. All authors read and approved the final manuscript.

\section{Funding}

This research was supported by the Ministry of Education, Science and Technology (NRF-2018R1A6A1A03025221).

\section{Availability of data and materials}

The datasets of the current study are available from the corresponding author on reasonable request.

\section{Declarations}

Ethics approval and consent to participate

This study was approved by the Institutional Review Board for Human Research of Daejeon University Daejeon Hospital (Approval Number: DJDSKH-21-E-23-1).

\section{Consent for publication}

Not applicable.

\section{Competing interests}

The authors declare that they have no competing interests.

\section{Author details}

${ }^{1}$ Institute of Bioscience \& Integrative Medicine, College of Korean Medicine, Daejeon Oriental Hospital of Daejeon University, Daedeok-Daero 176, Seo-Gu, Daejeon 35235, Republic of Korea. ${ }^{2}$ Department of Integrative Medicine, Graduate School of Integrative Medicine, CHA University, 120 Haeryong-Ro, Kyeong-Gi, Pocheon 11160, Republic of Korea. ${ }^{3}$ Department of Korean Rehabilitation Medicine, College of Korean Medicine, Daejeon University, Daedeok-Daero 176, Seo-Gu, Daejeon 35235, Republic of Korea. ${ }^{4}$ Health Insurance Review \& Assessment Service, Dunsanbuk-ro 121, Seo-Gu, Daejeon 35236, Republic of Korea. ${ }^{5}$ Department of Health Service Management, Daejeon University, 96-3 Yongun-Dong, Dong-Gu, 300-716, Daejeon 34520, Republic of Korea. 
Received: 1 October 2021 Accepted: 20 November 2021

Published online: 07 December 2021

\section{References}

1. Yoo EH, Choi ES, Cho SH, Do JH, Lee SJ, Kim JH. Comparison of fatigue severity and quality of life between unexplained fatigue patients and explained fatigue patients. Korean J Fam Med. 2018;39:180-4.

2. Pendergrast T, Brown A, Sunnquist M, Jantke R, Newton JL, Strand EB, Jason LA. Housebound versus nonhousebound patients with myalgic encephalomyelitis and chronic fatigue syndrome. Chronic IIIn. 2016;12:292-307.

3. Kapur N, Webb R. Suicide risk in people with chronic fatigue syndrome. Lancet. 2016;387:1596-7.

4. Bethesda M. Myalgic encephalomyelitis/chronic fatigue syndrome (ME/ CFS) research: workshop report. State of the knowledge workshop. National Institutes of Health. 2011. [2019 cited Mar, 25th]. 2019. https:// www.meassociation.org.uk/wp-content/uploads/2011/08/SoK-Works hop-Report-508-compliant-8-5-11.pdf.

5. Wong WS, Fielding R. Prevalence of chronic fatigue among Chinese adults in Hong Kong: a population-based study. J Affect Disord. 2010;127:248-56.

6. Estévez-López F, Mudie K, Wang-Steverding X, Bakken IJ, Ivanovs A, Castro-Marrero J, Nacul L, Alegre J, Zalewski P, Słomko J, Strand EB, Pheby D, Shikova E, Lorusso L, Capelli E, Sekulic S, Scheibenbogen C, Sepúlveda N, Murovska M, Lacerda E. Systematic review of the epidemiological burden of myalgic encephalomyelitis/chronic fatigue syndrome across Europe: current evidence and EUROMENE research recommendations for epidemiology. J Clin Med. 2020;9:1557.

7. Lim EJ, Ahn YC, Jang ES, Lee SW, Lee SH, Son CG. Systematic review and meta-analysis of the prevalence of chronic fatigue syndrome/myalgic encephalomyelitis (CFS/ME). J Transl Med. 2020;18:100.

8. Bakken IJ, Tveito K, Gunnes N, Ghaderi S, Stoltenberg C, Trogstad L, Håberg SE, Magnus P. Two age peaks in the incidence of chronic fatigue syndrome/myalgic encephalomyelitis: a population-based registry study from Norway 2008-2012. BMC Med. 2014;12:167.

9. Piccini P, Montagnani C, de Martino M. Gender disparity in pediatrics: a review of the current literature. Ital J Pediatr. 2018;44:1.

10. Institute of Medicine. Beyond myalgic encephalomyelitis/chronic fatigue syndrome; redefining an illness. Institute of medicine of the national academies. 2015. [cited 2019 Mar, 28th]. https://www.cdc.gov/me-cfs/ healthcare-providers/diagnosis/iom-2015-diagnostic-criteria.html.

11. Lim EJ, Son CG. Prevalence of chronic fatigue syndrome (CFS) in Korea and Japan: a meta-analysis. J Clin Med. 2021;10:3204.

12. Ranjith G. Epidemiology of chronic fatigue syndrome. Occup Med (Lond). 2005;55:13-9.

13. Bazelmans E, Vercoulen JH, Swanink CM, Fennis JF, Galama JM, van Weel C, van der Meer JW, Bleijenberg G. Chronic fatigue syndrome and primary fibromyalgia syndrome as recognized by GPs. Fam Pract. 1999;16:602-4.

14. Van Hoof E. The doctor-patient relationship in chronic fatigue syndrome: survey of patient perspectives. Qual Prim Care. 2009;17:263-70.

15. Cullinan J, Pheby DFH, Araja D, Berkis U, Brenna E, de Korwin JD, Gitto L, Hughes DA, Hunter RM, Trepel D, Wang-Steverding X. Perceptions of European ME/CFS experts concerning knowledge and understanding of ME/CFS among primary care physicians in Europe: a report from the European ME/CFS research network (EUROMENE). Medicina (Kaunas). 2021;57:208.

16. KOSIS. Korean statistic information service. 2021. [cited 2021 Aug, 1st]. https://kosis.kr/statisticsList/statisticsListIndex.do?menuld=M_01_01\& vwcd=MT_ZTITLE\&parmTabld=M_01_01\&outLink=Y\&entrType $=$.

17. Reyes M, Nisenbaum R, Hoaglin DC, Unger ER, Emmons C, Randall B, Stewart JA, Abbey S, Jones JF, Gantz N, Minden S, Reeves WC. Prevalence and incidence of chronic fatigue syndrome in Wichita. Kansas Arch Intern Med. 2003;163:1530-6.

18. Vincent A, Brimmer DJ, Whipple MO, Jones JF, Boneva R, Lahr BD, Maloney E, St Sauver JL, Reeves WC. Prevalence, incidence, and classification of chronic fatigue syndrome in Olmsted county, Minnesota, as estimated using the Rochester epidemiology project. Mayo Clin Proc. 2012:87:1145-52.
19. Lim EJ, Son CG. Review of case definitions for myalgic encephalomyelitis/ chronic fatigue syndrome (ME/CFS). J Transl Med. 2020;18:289.

20. Collin SM, Bakken IJ, Nazareth I, Crawley E, White PD. Trends in the incidence of chronic fatigue syndrome and fibromyalgia in the UK, 2001-2013: a clinical practice research datalink study. J R Soc Med. 2017;110:231-44

21. Bayliss K, Goodall M, Chisholm A, Fordham B, Chew-Graham C, Riste L, Fisher L, Lovell K, Peters S, Wearden A. Overcoming the barriers to the diagnosis and management of chronic fatigue syndrome/ME in primary care: a meta synthesis of qualitative studies. BMC Fam Pract. 2014;15:44.

22. Horton-Salway M. Bio-psycho-social reasoning in GPs' case narratives: the discursive construction of ME patients' identities. Health. 2002;6:401-21.

23. Speight N. Myalgic encephalomyelitis/chronic fatigue syndrome: review of history, clinical features, and controversies. Saudi J Med Med Sci. 2013;1:11-3.

24. Jung $\mathrm{JH}$, Park HK. Experiences of illness and socialization of suffering in patients with chronic fatigue syndrome. Health Soc Sci. 2016;8:5-38.

25. World Health Organization. ICD-10. 2019. [cited 2019 Mar, 16th]. https:// icd.who.int/browse10/2019/en\#/G93.3.

26. World Health Organization. ICD-11 for mortality and morbidity statistics. WHO. 2019. [cited 2019 Oct, 10th]. https://icd.who.int/browse11/l-m/ en\#/http://id.who.int/icd/entity/569175314.

27. Reynolds KJ, Vernon SD, Bouchery E, Reeves WC. The economic impact of chronic fatigue syndrome. Cost Eff Resour Alloc. 2004;2:1-6.

28. Capelli E, Zola R, Lorusso L, Venturini L, Sardi F, Ricevuti G. Chronic fatigue syndrome/myalgic encephalomyelitis: an update. Int J Immunopathol Pharmacol. 2010:23:981-9.

29. Chu L, Valencia IJ, Garvert DW, Montoya JG. Onset patterns and course of myalgic encephalomyelitis/chronic fatigue syndrome. Front Pediatr. 2019;7:12.

30. CDC. Centers for disease control and prevention. 2021. https://www.cdc. gov/me-cfs/about/index.html. Accessed 15 Aug 2021.

31. Valdez AR, Hancock EE, Adebayo S, Kiernicki DJ, Proskauer D, Attewell JR, Bateman L, DeMaria A Jr, Lapp CW, Rowe PC, Proskauer C. Estimating prevalence, demographics, and costs of ME/CFS using large scale medical claims data and machine learning. Front Pediatr. 2018;6:412.

32. Kim SH. Prevalence of chronic widespread pain and chronic fatigue syndrome in young Korean adults. J Musculoskeletal Pain. 2008;16:149-53.

33. Kim SH, Lee K, Lim HS. Prevalence of chronic widespread pain and chronic fatigue syndrome in Korean livestock raisers. J Occup Health. 2008; $50: 525-8$

34. Ji JD, Choi SJ, Lee YH, Song GG. Incidence and clinical manifestations of chronic fatigue in Korea. Korean J Med. 1999;56:738-44.

35. Ji JD, Choi YS, Chun BC, Choi SJ, Lee YH, Song GG. The prevalence and clinical manifestations of chronic fatigue syndrome in persons who visited health management center. Korean J Med. 2000;59:529-34.

36. Kim CH, Shin HC, Won CW. Prevalence of chronic fatigue and chronic fatigue syndrome in Korea: community-based primary care study. J Korean Med Sci. 2005:20:529-34.

37. Kim DY, Lee JS, Son CG. Systematic review of primary outcome measurements for chronic fatigue syndrome/myalgic encephalomyelitis (CFS/ME) in randomized controlled trials. J Clin Med. 2020;9:3463.

38. Solomon L, Reeves WC. Factors influencing the diagnosis of chronic fatigue syndrome. Arch Intern Med. 2004;164:2241-5.

39. Kim HG, Cho JH, Yoo SR, Lee JS, Han JM, Lee NH, Ahn YC, Son CG. Antifatigue effects of Panax ginseng CA Meyer: a randomised, double-blind, placebo-controlled trial. PLoS ONE. 2013;8(4):e61271.

40. Castro-Marrero J, Zaragozá MC, López-Vílchez I, Galmés JL, Cordobilla B, Maurel S, Domingo JC, Alegre-Martín J. Effect of Melatonin plus zinc supplementation on fatigue perception in myalgic encephalomyelitis/ chronic fatigue syndrome: a randomized, double-blind, placebo-controlled trial. Antioxidants (Basel). 2021;10(7):1010.

41. Eftekhari A, Dizaj SM, Chodari L, Sunar S, Hasanzadeh A, Ahmadian E, Hasanzadeh $\mathrm{M}$. The promising future of nano-antioxidant therapy against environmental pollutants induced-toxicities. Biomed Pharmacother. 2018:103:1018-27.

\section{Publisher's Note}

Springer Nature remains neutral with regard to jurisdictional claims in published maps and institutional affiliations. 